\title{
STRUCTURE, CONTROL AND REGULATION OF THE FORMAL MARKET FOR MEDICINAL PLANTS' PRODUCTS IN NIGERIA
}

\author{
Adegboyega E. Oguntade ${ }^{1 \S}$ and Isaac B. Oluwalana ${ }^{2}$ \\ ${ }^{1}$ Department of Agricultural Economics and Extension, Federal University of Technology, Akure \\ ${ }^{2}$ Department of Food Science and Technology, Federal University of Technology, Akure \\ Email: oguntadeade@yahoo.co.uk ${ }^{\$}$,ioluwalana2002@yahoo.com
}

\begin{abstract}
There are informal and formal markets for medicinal plants' products in Nigeria. The formal market is subject to the national regulatory framework for Food and Drug Administration and Control. It is relatively new and underdeveloped. This study was designed to appraise this market with special emphasis on the market participants, market structure, marketing functions performed, conduct of sellers in the market and; standards and regulations to which the market is subject. Information used for this study was collected through personal interviews and interactions with key participants in the market; especially the officials of regulatory agency. The market structure was analysed in terms of the share of market controlled by participants and product types. Concentration Ratios (CR2 and CR4) were used to assess the market share. Marketing functions being performed were described in terms of the exchange, physical and facilitating functions while the conduct was described in terms of pricing and promotional strategies. The regulatory framework under which the market operates was appraised. The market was highly concentrated with a CR2 and CR4 of $58.5 \%$ and $80.8 \%$; respectively. Imported products accounted for only $12.3 \%$ of the market. The predominant modes of presentation of the product were capsule $(41.6 \%)$ and liquid $(36.2 \%)$. About $20.77 \%$ of the products were classified as multivitamins, $13.85 \%$ were antibiotics while $10.77 \%$ addressed sexual dysfunctional problems. These products were regulated under the Food and Drug Administration and Control (NAFDAC) decrees, 1993-1999. Only 2.3\% of the products have received full registration status while the others were only listed.
\end{abstract}

Key words: Medicinal plants' products, Market structure, Standards and regulations

\section{Introduction}

Medicinal plants are one of the three main categories of plants that are described as herbs. The other two are flavouring and fragrance (Foster, 2006). Medicinal plants and their products are the basis of traditional medicines (Mafimisebi and Oguntade, 2010). They are also the starting materials for prescription drugs through compound purification or semi-synthetic processes. They also formed the basis of non-prescription (OTC) drugs, phyto-medicines and dietary supplements (Calixto, 2000). Herbs that are used for fragrance serve as the basis for the production of essential oils that are used for the enhancement in food, drugs, and cosmetics, fragrance materials for the perfume industry and as aromatherapy. Flavouring herbs are packaged and sold as spices to final consumers or to manufacturers for technical enhancement of commercial products (Foster, 2006)

The worldwide market for medicinal and aromatic plants, medicinal and vegetable saps and extracts, and vegetable alkaloids (pharmaceutical) was valued at about US\$8 billion. The market for spices and herbs was valued at US\$3 billion while that of cosmetics was valued at about US\$1.5 billion (Parke and Tikasingh, 2004). Medicinal plants are finding a new, expanding market as herbal components of health foods and preventative medicines, especially under the terms functional foods and nutraceuticals; and natural health products. They are often processed into a wide range of products including tablets, capsules, teas, tinctures, creams, oils, and liquids. The products tend to address the same ailments as over-the counter medications such as laxatives, weight-loss remedies, immune system enhancers, anti-aging remedies, and products to relieve anxiety and stress (Agriculture and Agri-Foods Canada, 2009). Many of these products are simply referred to as herbal medicines. According to WHO (1998a, 1998b) herbal medicines are finished, labeled medicinal products that contain as active ingredients, aerial or underground part of plants or other plant materials, or combination thereof, whether in the crude state or as plant preparations.

In Nigeria, two distinct markets for medicinal plants' products could be identified ${ }^{1}$. These are the (traditional) informal and the formal markets. A formal market has a legal regulatory framework within which market transactions are undertaken. On the contrary, for an informal market, there exists no specific legal regulatory framework. Operators within informal markets carry out their transactions based on norms and practices that have evolved in the markets over the years (Ortiz et.al. 2010). The informal market for medicinal plants and plant products in Nigeria has its roots in traditional medicine and it is widely spread across the country. A significant number of Nigerians, especially in rural/agricultural communities, depends on herbal medicines

\footnotetext{
${ }^{1}$ The market, considered from the product's dimension, refers to a group of consumers or organizations that is interested in the product, has the resources to purchase the product and is permitted by law and other regulations to acquire the product (Office of Fair Trading, 2004).
} 
obtained from the informal market for the treatments of various ailments (NBS, 2006; Mafimisebi and Oguntade, 2010). The formal market for medicinal plants' products on the other hand is relatively new and underdeveloped. It is formal because there is a legal regulatory framework in place, which provides some guidance to transactions in the market in Nigeria. This study appraised the formal market for medicinal plants' products in Nigeria with special emphasis on market participants and structure, marketing functions being performed, conduct of sellers in the market and; standards and regulations governing the market.

\section{Materials and methods}

The information used for this study was collected through personal interviews and interactions with key participants in the formal market for medicinal plants' products in Nigeria; especially the marketers of medicinal plants' products and officials of National Agency for Food and Drug Administration and Control (NAFDAC) ${ }^{2}$. Some official documents of the Agency were also consulted.

The market structure was analyzed in terms of the share of market controlled by participants and product types. Concentration Ratios (CR2 and CR4) were used to assess the level of concentration in the market. The marketing functions being performed by the participants in the market were described in terms of exchange, physical and facilitating functions being performed while the conduct was described in terms of pricing and promotional strategies. The regulatory framework, which defines the market as formal, was appraised.

The Concentration Ratios (CR2 and CR4) are the shares of the market being controlled by the two and four largest firms in the market. The share in this case was defined with respect to the number of products approved by the regulatory agency that are in the market. The higher the share controlled by a few firms, the more concentrated is the market.

\section{Results \\ Market structure}

Seven major participants in the formal market for the medicinal plants' products in Nigeria could be identified. These were the 'traditional medicine memory bank' (Okunlola, 2007), researchers (Odugbemi, 2007), entrepreneurs/producers, advertising agencies/media organizations, retailers, regulators (the most important being NAFDAC) and the consumers. These participants performed various functions and were active to various degrees.

It was difficult to establish a reasonable value for the market for medicinal plants' products. The market was relatively young and small in size. The survey yielded a total of 130 products that have been registered by NAFDAC. There were two distinct categories of suppliers in the market; namely; the local producers and distributors of imported products. Imported products accounted for $12.3 \%$ of the medicinal plants' products while local products accounted for the remaining $87.7 \%$ (Table $1)$.

The market was highly concentrated in terms of share of the market captured by marketers. Two firms accounted for $58.5 \%$ of the products being offered while four firms accounted for $80.8 \%$ of the products. Thirteen firms accounted for the remaining $12.3 \%$ or 16 products (Table 1 ).

The predominant mode of presentation of the products was capsule, which accounted for $41.6 \%$ of the products. This was followed by liquid, which accounted for $36.2 \%$ (Table 1 ).

About $97.7 \%$ of the products were given the status of "Listing" by NAFDAC while only $2.3 \%$ enjoys full registration (Table 1 ). A product is given the status of "Listing" by NAFDAC if the latter has subjected it to laboratory analysis to ascertain the chemical composition and non-toxicity of the chemical components but has not been subjected to clinical trials. The registration of a listed product is to be renewed every two years while for a product given full registration, renewal with NAFDAC is every five years.

Table 2 presents the distribution of the products based on the health issues addressed. About $20.77 \%$ of the products were classified as multivitamins, $13.85 \%$ were antibiotics while $10.77 \%$ addressed sexual dysfunctional problems.

\section{Marketing functions performed}

The marketing functions being performed by the participants in the market could be categorized into exchange, physical and facilitating functions (Crawford, 1997; Kohls and Uhl, 1990). Central to the market was the exchange function, i.e. buying and selling of medicinal plants' products while the physical and the facilitating functions ensured that the medicinal plants' products were available in the market. The entrepreneurs in the market processed medicinal plants into acceptable forms and distributed them across the market. The acceptable forms adopted include infusions, capsules, tablets, etc. (see Table 1). These are the critical physical functions that made the existence of the formal medicinal plants' products market possible.

The critical facilitating functions in the market were standardization, financing and risk bearing. The financing and risk bearing functions were being performed by the entrepreneurs while standardization in the market was ensured essentially by the regulatory activities of NAFDAC. The Advertising Practitioners Council of Nigeria regulates the conduct of its members thus

\footnotetext{
${ }^{2}$ NAFDAC is the regulatory agency for foods and drugs in Nigeria
} 
indirectly influencing the way medicinal plants' products were being advertised. NAFDAC also had regulations governing the advertisement of regulated products.

\section{Conduct in the market}

The formal market for medicinal plants' products was experiencing aggressive pricing and promotional strategies. Tie in sales was common. Some of the brands' were tying medical consultation and sales of products together. Brand promotion was intense especially among new entrants. The brand name was used to sell a family of products. The electronic media were the media of choice. Rather than operating through pharmacy shops and patent medicine outlets, medicinal plants' products made in Nigeria were mostly distributed through special outlets, which were aggressively advertised.

Table 1: Structure of the medicinal plants' products' market

\begin{tabular}{llrr}
\hline \hline Market structure & & Frequency & Percent \\
\hline & Local & 16 & 12.3 \\
Product origin & Total & 114 & 87.7 \\
\hline & CR2 & $\mathbf{1 3 0}$ & $\mathbf{1 0 0}$ \\
Market concentration & CR4 & & 58.5 \\
\hline & Capsule & & 80.8 \\
\hline & Cream & 54 & 41.6 \\
& Liquid & 1 & 0.8 \\
& Powder & 47 & 36.2 \\
Type of registration & Syrup & 8 & 6.2 \\
& Tablet & 4 & 3.1 \\
Mode of presentation & Tea bag & 14 & 10.8 \\
& Total & 2 & 1.5 \\
& Listing & $\mathbf{1 3 0}$ & $\mathbf{1 0 0}$ \\
\hline & Registered & 127 & 97.7 \\
& Total & $\mathbf{1 3 0}$ & 2.3 \\
\hline
\end{tabular}

Source: Authors' computation from market survey data

The distributors of imported medicinal plants' products used the electronic media less aggressively as their local counterparts. Their products were sometimes distributed through pharmacy shops and patent medicine outlets and through a chain of distributors and retailers within special incentive (bonuses) based schemes. The promotional messages were usually designed to present the products as natural and hence more beneficial to people. The products were also mostly offered as alternative medicine products.

\section{Standards and regulations governing the market}

The National Agency for Food and Drug Administration and Control (NAFDAC) Decrees (NAFDAC, 1993 - 1999) vests the power to set standards and regulate the manufacture, import and distribution of regulated foods and drugs in NAFDAC. The Decree states that the Agency shall, among others, regulate and control the importation, exportation, manufacture, advertisement, distribution, sale and use of food, drugs, cosmetics, medical devices, bottled water and chemicals; and conduct appropriate tests and ensure compliance with standard specifications approved by the Council for the effective control of the quality of foods, drugs, cosmetics, medical devices, bottled water and chemicals and their raw materials as well as their production processes in factories and other establishments. Thus from the subsisting NAFDAC decrees, local production, importation, exportation, manufacture, advertisement, distribution, sale and use of medicinal plants' products are subject to NAFDAC standards and regulations. NAFDAC regulations generally cover registration of manufacturers and products; and labeling and advertisement of products. 


\section{Registration of manufacturers and products}

The regulations in respect of registration of manufacturers state, among others, that an application for the registration of a regulated product shall be made by the manufacturer. If the manufacturer resides outside Nigeria, it shall be represented in Nigeria by a duly registered company or individual with facilities to effect recall of the product when necessary. An applicant for a manufacturer outside Nigeria must file evidence of Power of Attorney from the manufacturer which authorizes him to represent the manufacturer on all matters relating to the latter's specialties. The original Power of Attorney is to be notarized and submitted to NAFDAC. The manufacturer, in case of imported products, must show evidence that the company is licensed to manufacture the regulated product for sale in the country of origin. Such evidence must be prepared by the competent health authority of the country of manufacture and shall be authenticated by the Nigerian Mission in that country.

The regulations in respect of regulated products state, among others, that a food, cosmetic, medical device or bottled water product (regulated products) shall not be manufactured in Nigeria, unless the factory has been inspected and a certificate of recognition issued by NAFDAC. In the case of imported products, there must be evidences of registration of such products by the competent health authority of the country of manufacture i.e. products' licenses/certificates of registration. The evidences must indicate that the sale of the products does not constitute a contravention of the Food/Cosmetic/Medical Devices laws of that country. In the case of an imported new product, there must be evidence that such product is registered in the country of origin and the ingredients are approved raw materials. An applicant shall not be allowed to register a product in more than one brand name, except in cases where the manufacturers are different thus having different brand names for the same formulation.

A product is registered with a status of "Listing" by NAFDAC if the agency has subjected it only to laboratory analysis to ascertain the chemical composition and non-toxicity of the chemical components. To give full registration, NAFDAC must have subjected the product to laboratory analysis and clinical trials. The registration of a product with a status of "Listing" is to be renewed every two years while for a product with full registration; its registration must be renewed with NAFDAC every five years.

\section{Labeling and advertisement of products}

NAFDAC regulations on labeling state that labeling shall be informative and accurate. The minimum information that must appear on the label are the name of product, full location address of the manufacturer, batch number, date of manufacture and best before date; net contents of essential ingredients in metric weight in case of solids, semi-solids and aerosols, and metric volume in case of liquids. In the case of food, the ingredients must be listed by their common names in order of their preponderance by weight unless the food is standardized. Food additives and colours must be declared on the label. Spices, flavour and colours may be listed as such, without naming the specific material, but any artificial colour or flavour must be identified as such. The label must contain directions for safe use where appropriate or necessary on the information panel or on the package insert.

Table 2: Medicinal plants' products' classification (Source: Authors' computation from market survey data)

\begin{tabular}{lrr} 
Classification & Frequency & Percent \\
\hline Anti inflammatory & 4 & 3.08 \\
Antibiotics & 18 & 13.85 \\
Antiviral & 2 & 1.54 \\
Anti-hypertensive & 8 & 6.15 \\
Anti-malaria & 3 & 2.31 \\
Analgesics & 7 & 5.38 \\
Multivitamins & 27 & 20.77 \\
Fertility drug & 5 & 3.85 \\
Sexual dysfunction remedies & 14 & 10.77 \\
Bronchia dilators & 3 & 2.31 \\
Expectorants & 2 & 1.54 \\
Hypoglycemic drugs & 5 & 3.85 \\
Vaccines & 2 & 1.54 \\
Anti-neoplastic drugs & 4 & 3.08 \\
Anti-hemorrhoid & 7 & 5.38 \\
Others & 19 & 14.62 \\
\hline Total & $\mathbf{1 3 0}$ & $\mathbf{1 0 0}$ \\
\hline
\end{tabular}


When a food product is labelled with a claim of special dietary use, which includes claims of disease prevention, treatment, mitigation, cure or diagnosis, it must comply with the guidelines on drugs and registered as medicinal product. Advertisements for regulated products are to be submitted to NAFDAC for vetting and approval. Only NAFDAC registered products can be advertised. Documentation to be submitted to NAFDAC when seeking advertisement approval includes evidence of product registration, advertisement materials (television/radio script/storyboard, outdoor script/artwork, press script/artwork) and product samples in all pack sizes.

\section{Discussion \\ Market structure and conduct}

The prime movers of the formal medicinal plants' products market in Nigeria were the entrepreneurs. They were the active link between the traditional medicine and the medicinal plants' products formal market. The advertising agents/media played the role of deepening the market. The extent to which the market existed in the consciousness of Nigerian consumers was the result of the various advertisements that were conveyed through the electronic media. NAFDAC, the legal regulator of the market, succeeded in exerting its authority in the market and ensuring the need for certification of the products was appreciated by the key participants. The certification was also being used by some of the firms to adduce quality to their products in the course of marketing them.

The market was young and small in size. Most of the products were new and yet to mature in terms of product life cycle. Thus, if properly nurtured through appropriate standardization and regulations, the market can grow and contribute to the supply of healthcare products in Nigeria. The market was found to be highly concentrated when assessed in terms of origin (local/imported) of products, market share by the sellers, mode of presentation of the product and the registration status of the products. High concentration of the market implies inadequate competition and limited opportunity for choices by the consumers (UNCTAD, 2002). Inadequate competition can adversely affect the development of the market.

The physical and the facilitating functions performed by some participants in the market played critical roles in establishing the formal market for medicinal plants' products. Processing of medicinal plants into acceptable forms such as capsules, tablets, etc and the mode of distribution made them generally more acceptable. Traditional medicine whose accumulated knowledge has been feeding into the formal market for medicinal plants' products (Odugbemi, 2007) is sometimes associated with witchcraft (Mafimisebi and Oguntade, 2010) thus limiting its acceptance. The physical and the facilitating functions being performed by the participants in the formal market are helping to translate the knowledge and products available in traditional medicine into forms that are more standardized, acceptable and accessible. The regulatory and standardization roles being performed by NAFDAC have increased the acceptability of medicinal plants' products. The aggressive pricing and promotional strategies adopted by the firms has helped to give visibility to the products and to gradually establish the small but growing market.

\section{Standards and regulations governing the market}

NAFDAC regulations cover registration of manufacturers, registration of products, labeling of products and advertisement of products. The regulations for the registration of manufacturers ensure that only body corporate and/or legal persons are permitted to manufacture or import regulated products, which include medicinal plants' products that are traded in the formal markets in Nigeria. This ensures accountability for culpable activities under the applicable laws of Nigeria.

The regulations for the registration of products are designed to ensure that products are distinctly identifiable and that only products that meet the required local and international quality standards are given certifications. In this respect, laboratories set up by NAFDAC played a key role. The products must hence meet some minimum quality standards before being registered by NAFDAC. The registration of most of the products under "Listing Status" subjects them to re-assessment every two years whereas "Full Registration Status" requires re-assessment only after every five years. This will increase the opportunity to reassess and monitor the products.

The labeling guidelines ensure that consumers of the products are provided as much information as necessary to clearly identify what they are consuming, know how to safely use the products and to identify the source of the products they are consuming. The guidelines also provide a basis for following up on culpability when products are offered to consumers in contravention of the applicable local and international standards and regulations. The vetting of the advertisements of regulated products under the NAFDAC decrees is directed at ensuring that they are devoid of misleading information, half-truth, vague unsubstantiated statements, obnoxious and deceitful claims. The vetting is also to ensure that the advertisements do not contain statements that can promote irrational drug therapy (usage) or statements that disparage competing products. In general, these regulations have assisted in providing a standardized market framework which has increased the acceptability of medicinal plants' products.

In spite of the current status of the market, standards and regulations for the formal market for medicinal plants' products are still not fully developed. It is being regulated by NAFDAC under the NAFDAC Decrees and Regulations, $1993-$ 1999 which are designed to regulate food and drugs administration in general. The peculiarities of the young and developing medicinal plants' products market may not have been adequately covered. The issues that require specific regulatory attention 
include sources and method of collection of the medicinal plants' materials used in producing the products, the handling and mode of storage of the materials, etc which can affect the quality and efficacy of the final products (WHO, 2007).

In Canada, the Natural Health Product Regulations was put in place with effect from January 1, 2004 to regulate the medicinal plants' products' market. A specialized directorate, Natural Health Products Directorate, is responsible for administering the regulations. Previously, natural health products were classified as either foods or drugs under the Food and Drugs Act and Regulations. The regulations include provisions for definitions, product licensing, site licensing, good manufacturing practices, clinical trials, and labeling and packaging requirements. (Agriculture and Agri-Foods Canada, 2009). In the U.S., medicinal plants' products' market for humans is governed by the standards and regulations set by the Food and Drug Administration. Specifically, dietary supplements and phyto-pharmaceuticals are currently regulated under the US Dietary Supplement Health and Education Act, 1999. Dietary supplements are defined as "preparations that contain vitamins, minerals, and herbs which are used in addition to a normal "diet". While the Food and Drug Administration is responsible for regulation, the monitoring of advertising is the remit of the Food Trade Commission (Dvorkin, 2002).

The European Union is trying to establish common standards and regulations to govern the market. The "Guideline on Good Agricultural and Collection Practice (GACP) for Starting Materials of Herbal Origin" was published in 2006. The guideline is to ensure consistent quality of the herbal substances that are used in the manufacture of medicinal plants' products. The latest set of standards and regulations for the herbal products' market were published on $1^{\text {st }}$ September 2008 and took effect on $1^{\text {st }}$ September 2009 (European Commission, 2008). These relate to good manufacturing practice in respect of medicinal products which are meant for human and veterinary use. These efforts are being made given the special regulatory needs of the market.

\section{Conclusion}

We can clearly identify a small but growing formal market for medicinal plants' products in Nigeria. Special pricing and promotional strategies were being used to market the products. The applicable laws subject the local production, importation, exportation, manufacture, advertisement, distribution, sale and use of medicinal plants' products in Nigeria to NAFDAC standards and regulations. The application of these regulations has helped to create some confidence in the products being offered in the market. In spite of this, it is necessary to take another look at these standards and regulations as they affect medicinal plants' products given the special regulatory needs of the market. The issues that should be considered for specific attention include sources and methods of collection of the medicinal plants' materials used in producing the products, the handling and mode of storage of the materials, etc which can affect the quality and efficacy of the final products.

\section{References}

1. Agriculture and Agri-Foods Canada, (2009). Canada's Medicinal Plant Industry. Availabe at: http://www4.agr.gc.ca/AAFCAAC/display-afficher.do?id=1174597176899 (accessed 06-01-2011)

2. Calixto, J.B. (2000). Efficacy, safety, quality control, marketing and regulatory guidelines for herbal medicines phytotherapeutic agents). Braz J Med Biol Res 33(2): 179-189

3. Crawford I.M. (1997). Agricultural and Food Marketing Management, Food and Agriculture Organization of the United Nations, Viale delle Terme di Caracalla, 00100 Rome, Italy.M-62, Pp. 22-28.

4. Dvorkin, L. (2002). Aspects of herbal medicines regulation in Europe and the United States. The Pharmaceutical Journal, Vol 269 No 7216 p4032,

5. European Commission, 2008. The Rules Governing Medicinal Products in the European Union, Volume 4. EU Guidelines to Good Manufacturing Practice. Medicinal Products for Human and Veterinary Use._Available at: http://ec.europa.eu/health/ documents/eudralex/vol-4/index_en.htm\# (accessed 06-01-2011)

6. Foster, S. (2006). Worldwide Market Trends for Herb and Medicinal Plant Crops: Steps towards Building the Future. Regional Consultation on Linking Farmers to Markets, January $20-$ February $2^{\text {nd }}$, 2006 Available at: http://www.globalfoodchainpartnerships. org/Cairo/presentations/StevenFoster.pdf (accessed 06-01-2011)

7. Kohls, R.L. and Uhl, J.N. (1990). Marketing of Agricultural Products. 6th Edition, Macmillan Publishing Company, New York. Pp. 18-21

8. Mafimisebi, T.E. and Oguntade, A.E. (2010). Preparation and use of plant medicines for farmers' health in Southwest Nigeria: socio-cultural, magico-religious and economic aspects. Journal of Ethnobiology and Ethnomedicine, 6:1doi:10.1186/1746-42696-1

9. NAFDAC (1993- 1999). National Agency for Food and Drug Administration and Control (NADAC) Decrees and Regulations, Government Press, various issues, Lagos, 1993 - 1999

10. NBS, (2006). Nigerian Core Welfare Indicators. National Bureau of Statistics. Available at:http://www.nigerianstat.gov.ng/nbsapps/cwiq/2006/survey0/outputInformation/cwiqreports.html (accessed 06-01-2011)

11. Odugbemi, T. (2007). Medicinal Plants from Nigeria: Challenges for a New Spirit and Teamwork. Proceedings of the AkureHumboldt Kellogg/ 3rd SAAT Annual Conference on Medicinal Plants in Agriculture: Nigerian Experience, $16^{\text {th }}-19^{\text {th }}$ April 2007

12. Office of Fair Trading, UK (2004). "Market Definition: Understanding Competition Law" Available at:http://www.oft.gov.uk/shared_oft/business_leaflets/ca98_guidelines/oft403.pdf (accessed 06-01-2011) 
13. Okunlola, J.O. (2007). The Sociology of the Use of Medicinal Plants. Proceedings of the Akure-Humboldt Kellogg/3rd SAAT Annual Conference on Medicinal Plants in Agriculture: Nigerian Experience, $16^{\text {th }}-19^{\text {th }}$ April 2007

14. Ortiz, N.C.M., C. Campbell and Hyman, B. (2010). Analyzing Market Reforms and Food Distribution Systems in Accra, Ghana: Lessons and Implications for Reforming the Bazurto Market of Cartagena, Colombia, Massachusetts Institute of Technology, Department of Urban Studies and Planning Case Study. Available at:http://colabradio.mit.edu/ alexam/colabradio/wpcontent/uploads/2010/02/CasodeEstudio_Ghana.pdf (accessed 06-01-2011)

15. Parke A. and T. Tikasingh (2004). The Global Market for Herbal Products and Pertinent Trade Issues. webiica.iica.ac.cr/Trinidad and Tobago/ppt/ Globalherbal.ppt. Available at: http://www.docin.com/p-67770668.html (accessed 06-01-2011)

16. UNCTAD, (2002). Objectives of competition law and policy: Towards a coherent strategy for promoting competition and development. Note by the UNCTAD secretariat, United Nations Conference on Trade and Development. Available at: http://www.ifc.org/ifcext/fias.nsf/AttachmentsByTitle/Conferences_CompetitionPolicyTanz_Hassan+Qaqaya.prn.pdf/\$FILE/Con ferences_CompetitionPolicyTanz_Hassan+Qaqaya.prn.pdf (accessed 06-01-2011)

17. WHO, (1998)a. Regulatory situation of herbal medicines: A worldwide review. Bulletin of the World Health Organization, Geneva, 1-43 Available at: http://whqlibdoc.who.int/ hq/1998/WHO TRM 98.1.pdf (accessed 06-01-2011)

18. WHO, (1998)b. Quality control methods for medicinal plant materials. World Health Organization, Geneva. Available at: http://apps.who.int/medicinedocs/pdf/h1791e/ h1791e.pdf (accessed 06-01-2011)

19. WHO, (2007).WHO Guidelines on Good Manufacturing Practices (GMP) for Herbal Medicines, World Health Organization, Geneva, 72 pp. Available at http://apps.who.int/medicinedocs/index/assoc/s14215e/s14215e.pdf (accessed 06-01-2011) 